\title{
Chromatographic Identification of Leaf Color Characteristics on Fine-Flavor and Bulk Cacao as Selection Indicator
}

\author{
Indah Anita-Sari ${ }^{1 *}$, Bayu Setyawan ${ }^{1)}$, Marcelinus A.S. Adhiwibawa ${ }^{2)}$ \\ and Agung Wahyu Susilo' \\ ${ }^{1)}$ Indonesian Coffee and Cocoa Research Institute, J1. PB. Sudirman 90, Jember Indonesia \\ ${ }^{2)} \mathrm{Ma}$ Chung University, Jl. Villa Puncak Tidar N-01, Malang, 65151, Indonesia \\ ${ }^{*}$ Corresponding author: indah.sari83@yahoo.com \\ Received: 21 February 2016 / accepted: 27 March 2016
}

\begin{abstract}
A problem encountered in plant breeding process to determine bean color quality of fine-flavor cocoa is a long selection period. Preliminary results indicated that the fine-flavor cocoa has a low color reflectance than bulk cocoa. The objective of this study is to find more applicable and easier method to do the early detection of fine-flavor cocoa on the breeding population. Detection of the leaf color characteristics was done by chromatographic and spectrophotometry analysis. Chromatographic analysis was carried out in Kaliwining Experimental Station, Indonesian Coffee and Cocoa Research Institute using complete random design consisted of two types of cocoa; fine-flavor (10 clones) and bulk cocoa (10 clones). Spectrophotometric analysis was conducted at Ma Chung University, Malang, East Java. Four clones of bulk cocoa and six clones of fine flavor cocoa were used in this analysis. The results of the study showed that the flush color characteristics of the fine-flavor cocoa were different from the bulk cocoa characteristics as shown by the differences in the value of $L^{*}, b^{*}$ and anthocyanin content. Flush characteristics of the fine-flavor cocoa had brighter color, more toward green with higher yellow level, while the bulk cocoa had darker flush, red and lower yellow level. The color parameter of $\mathrm{L}^{*}$ and $\mathrm{b}^{*}$ had a higher genetic variation compared with the environment variation. However, the parameter $\mathrm{a}^{*}$ had a higher environmental variation compared with genetic variation. Grouping of fine-flavor cocoa and bulk cocoa could be done through the detection of flush anthocyanin content, when tendency of flush anthocyanin content on fine-flavor cocoa was lower than bulk cocoa. The detection of flush color particularly $\mathrm{L}^{*}$ and $\mathrm{b}^{*}$ parameters through chromatographic analysis and anthocyanin content through spectrophotometric analysis may be used as a criteria for selection the fine flavor cocoa on seedling phase.
\end{abstract}

Keywords: leaf color characteristic, fine-flavor cocoa, bulk cocoa, selection indicator

\section{INTRODUCTION}

Cocoa is the third largest plantation commodity that gives contribution to the national foreign exchange after palm oil and rubber. There is an increasing demand for cocoa beans due to rapid growth of chocolate industry both in domestic and international level which results in competitiveness in product quality produced such as taste and flavor. One method to increase chocolate flavor is to use fine-flavor cocoa that genetically has good flavor quality, as the results, there is $10 \%$ increase in annual demand of the fine-flavor cocoa in domestic and 
international market (Gockowski et al., 2011; Anita-Sari et al., 2012). However, production of fine-flavor cocoa bean cannot meet the increasing demand; one of the causes is some pests and diseases infecting cocoa plant especially vascular streak dieback.

The main characteristic that distinguishes fine-flavor cocoa from bulk cocoa is the color of beans. The color of the fine-flavor bean is white, while the bulk cocoa is purple. When there is $20 \%$ of purple-colored cocoa bean among the white-colored fine-flavor cocoa beans, quality of the fine-color cocoa is decreasing. There is a promising chance for the fine-flavor cocoa beans in the chocolate industry where the price of the fine-flavor cocoa is 2.5 times higher than that of bulk cocoa. It has become opportunity and challenge for Indonesia as one of the largest producer of fine-flavor cocoa to increase production that declines in volume recently. One method to increase production is to provide high quality of fine-flavor cocoa planting material. However until now, number of fine-flavor cocoa clones with superior quality is very limited and most of them are likely be infected by VSD.

One of the obstacles in breeding process of fine-flavor cocoa plants is a long selection period because one has to wait for the plants to produce some seeds in order to be able to determine which color of seeds have produced. Some efforts have been undertaken to find out some criteria functions as initial indicator for the selection of fineflavor cocoa, for example identifying the color of anthocyanin flowers (Iswanto \& Winarno, 1997) and identifying initial correlation between flush color reflectance of fine-flavor cocoa and bulk cocoa (Adhiwibawa et al., 2015). A preliminary result showed that fine-flavor cocoa has lower flush color reflectance compared to bulk cocoa. Color reflectance may have influence towards anthocyanin level and leaf color that can be observed using other methods such as chromatograph and spectrophotometer. Gamon \& Surfus (1999) argued that the reflectance ratio between red and green in spectrum is an effective indicator to predict ratio of anthocyanin and chlorophyll during leaf development. Each color has different wave length. Red has the longest wave length and violet has the shortest one. Every plant requires different color to manage its growth, for example growth and flowering inhibition (Anonym, 2005). Sims \& Gamon (2002) mentioned that pigment has correlation with physiological function of leaf. Chlorophyll absorbs light and transfers it in the process of photosynthesis. Morphological identification can be used to identify germplasm collections using genetic prediction and correlation between morphological characteristic and other significant characteristics as the approach (Rimoldi et al., 2010). Identification at morphological level is especially needed to identify a phenotype and some changes related to its ecotype (Marzuki et al., 2008). Genetic variance between individuals or populations can be done using morphological marking (Garcia et al., 1998). Taking the advantages, color parameter as one of selecting indicators has been conducted frequently, for example in a study of Kristamtini et al. (2014) on rices. The results revealed that there was negative correlation between color parameter $\mathrm{L}^{*}, \mathrm{a}^{*}$ and $b^{*}$ and the total anthocyanin. The finding was used as a guide in the selection of rice variety with high amount of anthocyanin and using color parameter as practical indicator in the selection.

Leaf development phase is a vital stage to pay attention in determining some criteria that become the basis of selection indicators. Different leaf color trend between fine-flavor cocoa and bulk cocoa is expected to be initial criteria in selection process of fine-flavor cocoa breeding more particularly in the result 
of cross-breeding. Some efforts have to be carried out in order to get more applicable and easier method to be able to detect the initial result of fine-flavor cocoa and bulk cocoa crossbreeding. It is expected that this result can provide some information to support the fineflavor cocoa breeding program eventually that selection can be done as early as possible; which will affect the breeding process acceleration to get the superior quality of fineflavor cocoa.

\section{MATERIALS AND METHODS}

\section{Chromatograph Analysis}

Location of this study was in Kaliwining Experimental Station, Indonesian Coffee and Cocoa Research Institute (ICCRI) located in Jember, East Java. Layout of this experiment was completely randomized design using two types of cocoa namely fine-flavor cocoa and bulk cocoa. Each type of cocoa was represented by ten collection clones and repeated three times. Fine-flavor cocoa clones used involved DR 2, PNT 17, PNT 16, PNT 37, PNT 38, PNT 8, DR 38, PNT 12, PNT 30 and PNT 33, while for bulk cocoa clones were Sulawesi 1, KW 617, ICCRI 04, ICCRI 07, MCC 02, Sulawesi 2, Sca 6, Sulawesi 3, MCC 01 and ICCRI 03.

Method of observation was based on chromatograph analysis using Conica Minolta equiped with direct integrity for the light (L) score conversion, red and green chromatic color mixture (a), and blue and yellow chromatic color mixture (b). Hunter color notation system was characterized using three parameters, $\mathrm{L}$, $\mathrm{a}$, and $\mathrm{b}$ where scoring range for each of the parameter started from 0 to 100 . $\mathrm{L}$ is the parameter of light. The range of score starts from 0 (black) to 100 (white). Notation L represents reflecting light illumi- nation which results in achromatic color of white, grey and black. Notation a shows red and green chromatic color mixture. $+\mathrm{a}$ (positive) score starts from 0 up to 100 for red and $-\mathrm{a}$ (negative) score starts from 0 to -80 for green. Notation $b$ shows blue and yellow chromatic color mixture with notation $+b$ (positive) from 0 until +70 for yellow and -b (negatif) from 0 to -70 for blue (Soekarto, 1990). The method of data analysis was contrast test and grouping was carried out based on the principle component analysis (PCA) with SAS 9.1. program.

\section{Spectrophotometer Analysis}

The setting of the study was in Kaliwining Experiment Station ICCRI in Jember, East Java, while the spectrophotometer analysis was conducted in Ma Chung University, Malang, East Java. Layout of this experiments was completely randomized design using two types of cocoa namely fine-flavor cocoa and bulk cocoa. The bulk cocoa used in the analysis were MCC 01, KW 617, Sulawesi 1 and MCC 02, whereas the fineflavor cocoa used were DR 1, ICCRI 01, PNT 16, PNT 17, DRC 16 and ICCRI 02.

Sims \& Gamon (2002) method was the reference for spectrophotometer analysis for fine-flavor cocoa and bulk cocoa flush color analysis using the spectrophotometer on the wave length of 530 and $640 \mathrm{~nm}$. The analysis was used to measure red color absorption. The highest absorbent score can be obtained using the spectrophotometer. Thus, no red color component in the flush results in failing formation of absorbent on the wave length between $400-700 \mathrm{~nm}$. The analysis of the spectrophotometer data is carried out by finding out mean anthocyanin concentration in each accession used and grouping was conducted by making scatter using Excell 2010 program. 


\section{RESULTS AND DISCUSSION}

\section{Chromatograph Analysis}

Result of the analysis shows there is a discrepancy between leaf color characteristics between fine-flavor and bulk cocoa. Chromatograph analysis showed there was an obvious difference found on the flush of the two types of cocoa tested. Bulk cocoa had lower $\mathrm{L}^{*}$ (light) score compared to fine-flavor cocoa. On the other hand, bulk cocoa had higher $a^{*}$ score than fine-flavor cocoa. $b^{*}$ score of both types of cocoa did not show any obvious difference (Table 1).

There was no difference in leaf color characteristics between young and old leaves of fine-flavor and bulk cocoa indicated by relatively similar $\mathrm{L}^{*}, \mathrm{a}^{*}, \mathrm{~b}^{*}$ scores. According to Soekarto (1990), $\mathrm{L}^{*}$ score shows direct integrity for the level of brightness, $a^{*}$ score shows red and green chromatic color combination, and $b^{*}$ score shows blue and yellow chromatic color combination. Based on the $\mathrm{L}^{*}$ scores, fine-flavor cocoa had lighter/ brighter color than bulk cocoa. Notation L* shows reflecting light illumination that results in achromatic color of white, grey and black. Bulk cocoa has stronger red color as shown by $+a$ (positive) score, while flush color of fine-flavor cococa was greenish as shown by -a (negative) score. Both types of cocoa had positive $b^{*}$ scores which means that flush tends to be yellowish and fineflavor cocoa has stronger shades of yellow compared to bulk cocoa. According to Adhiwibawa et al. (2015), DRC 16 clone had the largest color reflectance shown by the lowest level of anthocyanin. That finding is in line with the results of this study that showed fine-flavor cocoa had always lower trend of a* score compared to bulk cocoa on their flush, young and old leaves. Result of PCA analysis showed that accession categorized as fine-flavor cocoa tended to be closer to each other forming a group, and so does that bulk cocoa (Figure 1). This finding is in line with the results of flush color reflectance conducted by Adhiwibawa et al. (2015) between bulk cocoa (Sulawesi 1 and MCC 01) and fine-flavor cocoa (DR 1 and DR 2). The result of chromatograph analysis supports the opinion that flush color character of fine-flavor cocoa is different from that of bulk cocoa even though it is analyzed using different methods.

The preliminary identification carried out for flush color reflectance is also represented in the result of analysis using chromatograph method. Sims \& Gamon (2002) found that color analysis could be conducted by conventional method using extraction and spectrophotometer or HPLC by doing destruction or leaf measuring. On the other hand, color reflectance is a non-destructive, fast and widely applicable method. There is different color stability shown on the result of flush color reflectance (Adhiwibawa et al., 2015) and more specifically the $\mathrm{L}^{*}$ and $\mathrm{a}^{*}$ scores on the result of chromatograph analysis of both types of cocoa indicate that the character can be used as one of the criteria to distinguish fine-flavor and bulk cocoa in the preliminary selection where the characteristics of fineflavor are lighter greenish flush color with stronger of yellow color, while those of bulk cocoa are darker, reddish flush color with lower level of yellow.

$\mathrm{L}^{*}$ and $\mathrm{b}^{*}$ mean color parameters on the 10 clones of fine-flavor cocoa showed higher score than bulk cocoa while a* score was lower than bulk cocoa (Table 2). L* and $b^{*}$ color parameters had higher genetic variance than environmental variance. However, $a^{*}$ parameter showed the environmental variance was higher than the genetic variance. It shows that $\mathrm{L}^{*}$ and $\mathrm{b}^{*}$ variance parameter was influenced by genetic factor more than environmental factor (Kristamtini et al., 2014). Color parameter is a characteristic with a little influence from gen and qualitative in nature. 
Table 1. Orthogonal contrast test of leaf color characters on bulk and fine flavor cocoa

\begin{tabular}{|c|c|c|c|c|c|c|c|c|c|}
\hline \multirow{2}{*}{ Treatment } & \multicolumn{3}{|c|}{ Flush } & \multicolumn{3}{|c|}{ Younger leaf } & \multicolumn{3}{|c|}{ Older leaf } \\
\hline & $\mathrm{L}^{*}$ & $a^{*}$ & $b^{*}$ & $\mathrm{~L}^{*}$ & $a^{*}$ & $b^{*}$ & $\mathrm{~L}^{*}$ & $a^{*}$ & $b^{*}$ \\
\hline Bulk Cocoa & $36.62 \mathrm{~b}$ & $9.07 \mathrm{a}$ & $11.55 \mathrm{a}$ & $43.11 \mathrm{a}$ & $-10.46 \mathrm{a}$ & $22.94 \mathrm{a}$ & $35.08 \mathrm{a}$ & $-9.51 \mathrm{a}$ & $12.33 \mathrm{a}$ \\
\hline Fine Cocoa & $41.75 \mathrm{a}$ & $-2.84 b$ & $21.06 \mathrm{a}$ & $45.13 \mathrm{a}$ & $-14.67 \mathrm{a}$ & $28.11 \mathrm{a}$ & $37.17 \mathrm{a}$ & $-11.59 \mathrm{a}$ & $15.25 \mathrm{a}$ \\
\hline
\end{tabular}

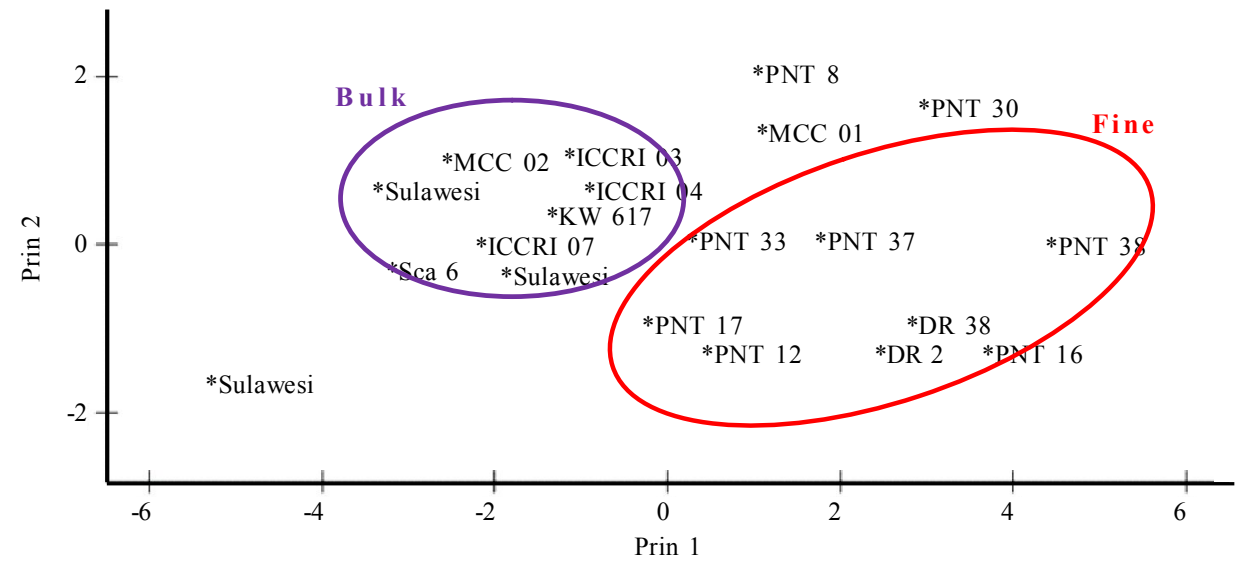

Figure 1. PCA analysis on fine flavor and bulk cocoa based on $\mathrm{L}^{*}, \mathrm{a}^{*}, \mathrm{~b}^{*}$ value

Table 2. Average of $\mathrm{L}^{*}, \mathrm{a}^{*}, \mathrm{~b}^{*}$, genetic variation, and environment variation on some accession of fine flavor and bulk cocoa

\begin{tabular}{|c|c|c|c|}
\hline Accession & $\mathrm{L}^{*}$ & $a^{*}$ & $\mathrm{~b}^{*}$ \\
\hline \multicolumn{4}{|l|}{ Bulk Cocoa } \\
\hline Sulawesi 1 & $35.29 \pm 2.45$ & $11.80 \pm 1.85$ & $10.00 \pm 2.23$ \\
\hline KW 617 & $38.70 \pm 3.67$ & $11.56 \pm 0.92$ & $12.27 \pm 3.35$ \\
\hline ICCRI 04 & $39.18 \pm 3.22$ & $8.24 \pm 1.67$ & $14.33 \pm 2.21$ \\
\hline ICCRI 07 & $36.34 \pm 1.44$ & $12.56 \pm 0.47$ & $10.68 \pm 1.97$ \\
\hline MCC 02 & $32.00 \pm 0.69$ & $9.46 \pm 1.08$ & $7.69 \pm 2.78$ \\
\hline Sulawesi 2 & $34.55 \pm 3.27$ & $10.69 \pm 1.31$ & $9.54 \pm 3.89$ \\
\hline Sca 6 & $37.54 \pm 1.44$ & $5.82 \pm 2.05$ & $11.02 \pm 4.09$ \\
\hline Sulawesi 3 & $37.91 \pm 4.01$ & $11.10 \pm 0.98$ & $12.97 \pm 2.44$ \\
\hline MCC 01 & $38.21 \pm 2.71$ & $2.49 \pm 1.16$ & $15.49 \pm 1.51$ \\
\hline \multicolumn{4}{|l|}{ Fine Cocoa } \\
\hline DR 2 & $45.27 \pm 3.18$ & $-4.23 \pm 4.01$ & $22.97 \pm 3.53$ \\
\hline PNT 17 & $40.57 \pm 1.95$ & $3.09 \pm 4.02$ & $17.69 \pm 1.65$ \\
\hline PNT 16 & $47.76 \pm 2.10$ & $-11.04 \pm 2.42$ & $25.86 \pm 3.25$ \\
\hline PNT 37 & $39.93 \pm 1.89$ & $-1.50 \pm 1.79$ & $21.38 \pm 0.97$ \\
\hline PNT 38 & $43.50 \pm 1.58$ & $-3.67 \pm 1.67$ & $30.11 \pm 0.91$ \\
\hline PNT 8 & $37.34 \pm 0.62$ & $2.26 \pm 2.16$ & $13.94 \pm 5.21$ \\
\hline PNT 12 & $42.92 \pm 4.09$ & $-7.81 \pm 4.61$ & $22.29 \pm 3.92$ \\
\hline DR 38 & $43.45 \pm 4.01$ & $-4.93 \pm 5.01$ & $23.09 \pm 4.10$ \\
\hline PNT 30 & $45.69 \pm 6.07$ & $-3.49 \pm 4.79$ & $17.29 \pm 1.43$ \\
\hline PNT 33 & $38.05 \pm 1.68$ & $2.93 \pm 0.18$ & $16.00 \pm 1.42$ \\
\hline$\sigma_{g}^{2}$ & 11.82 & 4.93 & 34.11 \\
\hline$\sigma_{\mathrm{e}}^{2}$ & 8.38 & 7.50 & 10.89 \\
\hline
\end{tabular}

Notes: Figures are means $\pm \mathrm{SE} ; \sigma 2 \mathrm{~g}=$ genotype variation; $\sigma 2 \mathrm{e}=$ environment variation. 
Syukur \& Sobir (2015) mentioned that qualitative nature was determined by one or two gen, had little influence from environment and could be selected visually.

Kristamtini et al. (2014) reported that a characteristic with high score of genetic variance can be modified through direct selection. The score had high genetic variance and can be said as having wide genetic variance. Wide genetic variance is one of the requirements to conduct selection to particular characteristic and the selection to the characteristic is more efficient (Bahar \& Zein, 1993). In relation to selection program using $\mathrm{L}^{*}, \mathrm{a}^{*}$ and $\mathrm{b}^{*}$ as color parameters, it is advantageous to identify differences between the types of cocoa, particularly the fine-flavor cocoa and bulk cocoa, besides, it helps selecting of parents in crossing. It can be carried out by identifying cultivar and result of grouping based on nearly identical and identical characteristics that facilitate the breeding process.

\section{Spectrophotometer Analysis}

Result of spectrophotometer analysis showed that there was different trend of anthocyanin level between fine-flavor and bulk cocoa (Figure 3). Bulk cacao had higher flush color anthocyanin level compared to fine-flavor cocoa.

In general, the level of anthocyanin content in flush of bulk cocoa was higher than that of fine-flavor cocoa (Table 3). MCC 01 that is categorized as bulk cacao had lower level of flush anthocyanin and similar to fine-flavor cocoa. On the other hand, PNT 17 that is categorized as fine-flavor cocoa had high anthocyanin level. Such discrepancy may occur due to the influence of genetic or environmental factors or even interaction between the two. Most color dimension is integral in nature. Distance or scale between two points shows that there is difference in color of fresh cocoa beans on the spectrum of purple, red, and yellow (Cakirer, 2003). White until purple colors completely depends upon the amount of anthocyanin (Camu et al., 2008).

Levels of anthocyanin and colorimeter scores in the brightness of cocoa beans represent the actual score of anthocyanin level of the cocoa beans (Cakirer, 2003). Darker color on the surface of cocoa beans indicates higher amount of anthocyanin on the extract of the beans (Anita-Sari et al., 2012). Similar to the result of spectropho-

\begin{tabular}{lc} 
Table $3 . \quad$ Anthocyanin content on flush using spectrophotometry analysis & \\
\hline Accession & Anthocyanin content, $\mu \mathrm{mol} / \mathrm{L}$ \\
\hline Bulk & $2,558 \pm 1.86$ \\
MCC 01 & $10.36 \pm 5.16$ \\
KW 617 & $38.95 \pm 3.61$ \\
SUL.1 & $62.14 \pm 6.01$ \\
MCC 02 & \\
Fine & \\
DR 1 & $2.20 \pm 1.87$ \\
ICCRI 01 & $8.39 \pm 1.56$ \\
PNT 16 & $4.82 \pm 0.49$ \\
PNT 17 & $31.11 \pm 1.78$ \\
DRC 6 & $1.26 \pm 0.86$ \\
ICCRI 02 & $8.09 \pm 2.61$ \\
\hline
\end{tabular}




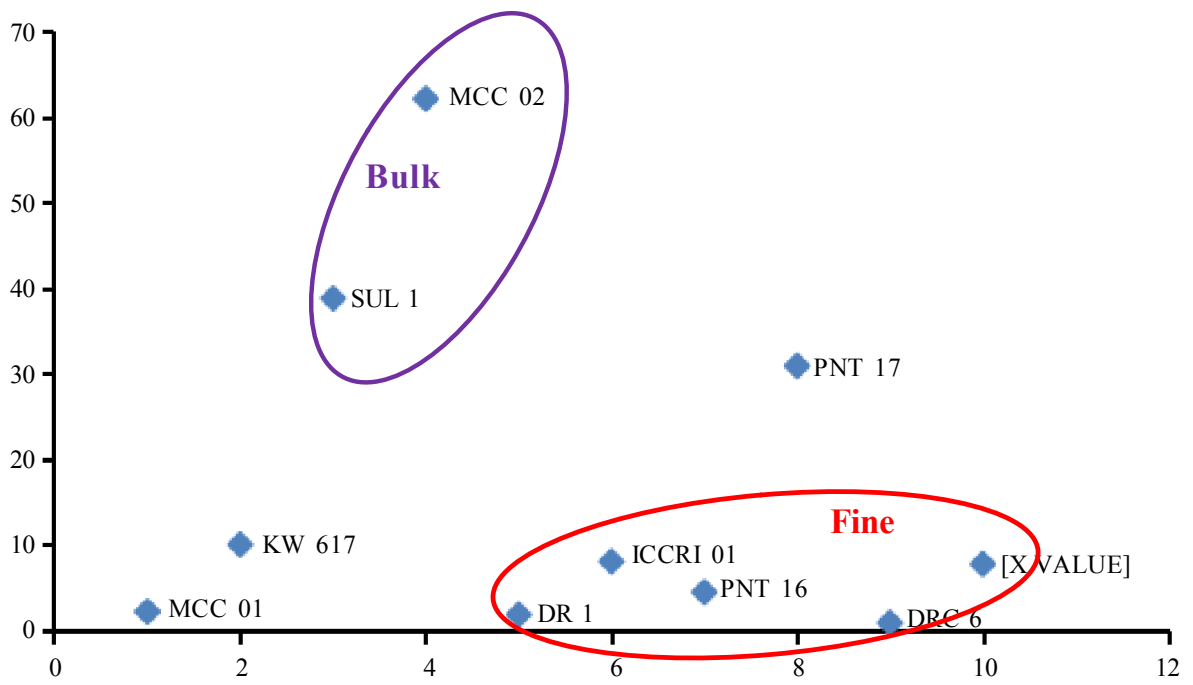

Figure 2. Spectrophotometry analysis of flush antocyanin content on fine-flavor and bulk cocoa

tometer analysis on flush color, bulk cocoa showed higher level of anthocyanin and as the result surface of the flush in bulk cocoa was darker as the effect of anthocyanin level of the flush extract. Different color character of the beans is influenced by precursor that forms color component, for example flavonoid that is categorized as polyphenol (Popov-Raljic \& Lalicic-Petronijevic, 2009).

Result of correlation analysis showed that $\mathrm{L}^{*}$ score had negative correlation with $a^{*}$ score and the level of anthocyanin. $b^{*}$ score had also negative correlation with the level of anthocyanin. On the other hand, $a^{*}$ score showed positive correlation with the level of anthocyanin, $L^{*}$ score and $b^{*}$ score (Table 4).

Different from the previous result of Kristamtini et al. (2014) study on rice color, where $\mathrm{L}^{*}$ and $\mathrm{b}^{*}$ scores showed negative correlation with the level of anthocyanin of cocoa flush. It showed that the higher $\mathrm{L}^{*}$ and $b^{*}$ scores were, the lower level of anthocyanin flush was and as the effect the color formed was getting darker. On the other hand, if $a^{*}$ score was high, the level of anthocyanin flush was getting higher. There is a negative correlation in $\mathrm{L}^{*}$ and $\mathrm{b}^{*}$ with the total level of polyphenol and antioxidant capacity (Yodmanee et al., 2011; Shen et al., 2009). Negative correlation between $b^{*}$ and total anthocyanin can take place because $b^{*}$ will have negative score if the color being formed is closer to blue and positive score if the color is yellowish. In conclusion, the lower $b^{*}$ score is the higher level of anthocyanin in the flush (Kristamtini et al., 2014).

Different flush color between fine-flavor cocoa and bulk cocoa analyzed using three different methods proves that level of flush color can be used as morphological marker in early detection of fine-flavor cocoa as the result of cross-breeding before the plants produce any beans. Kristamtini et al. (2014) found that different $\mathrm{L}^{*}, \mathrm{a}^{*}$ and $\mathrm{b}^{*}$ scores in rice could be used as a guide in variety development selection and the color parameter can be used as practical indicator in selection process. 
Table 4. Correlation analysis of $\mathrm{L}^{*}, \mathrm{a}^{*}, \mathrm{~b}^{*}$ and antocyanin content on cocoa flush

\begin{tabular}{lrrrr}
\hline & $\mathrm{L}$ & $\mathrm{a}^{*}$ & $\mathrm{~b}^{*}$ & Antocyanin \\
\hline $\mathrm{L}^{*}$ & - & & & \\
$\mathrm{a}^{*}$ & -0.87 & - & & \\
$\mathrm{b}^{*}$ & 0.97 & 0.97 & - & \\
Antocyanin & -0.80 & 0.62 & -0.77 & - \\
\hline
\end{tabular}

\section{CONCLUSION}

Flush color characteristic of fine-flavor cocoa is different from bulk cocoa that is shown by different $\mathrm{L}^{*}$ and $\mathrm{b}$ *scores as well as level of anthocyanin. Fine-flavor cocoa has lighter, green flush color and stronger yellow color while bulk cocoa has darker, red flush color and lower level of yellow. Identifying anthocyanin level on the flush, where there is a tendency that fine-flavor cocoa has lower level of anthocyanin on the flush than bulk cocoa, it can be used as the basis to put into the two types of cocoa category. Detecting flush color specifically $L^{*}$ and $b^{*}$ parameters through chromatograph and anthocyanin level analysis using spectrophotometer analysis can be used as a guide in selecting and developing variety and as practical indicator to select which fine-flavor cocoa seedis.

\section{ACKNOWLEDGEMENT}

The authors would like to thank Ir. Yusianto for his intensive guidance for the study until successfully been conducted. The authors would also send their gratitude to the technicians in Cocoa Plant Breeding Laboratory in their contributions to the study.

\section{REFERENCES}

Adhiwibawa, M.A.S.; I. Anita-Sari; K.R. Prilianti; A.W. Susilo; I. Limantara \& T.H.P Brotosudarmo (2015). Rapid determination of anthocyanin in cocoa (Theobroma cacao L.) leaves using digital image processing for fine cocoa clones selection. $10^{\text {th }}$ International Symposium on Modern Optics and Its Applications. 10-13 August 2015.

Anita-Sari, I.; A.W. Susilo \& Yusianto (2012a). Pengkayaan materi genetik "A Java light breaking cocoa" melalui kegiatan seleksi dan eksplorasi pada populasi kakao edel di wilayah Jawa Timur. Seminar Nasional Insentif Riset Sinas. Bandung, 29-30 November 2016, 12-16.

Anita-Sari, I.; A.W. Susilo; Yusianto \& S. Wardani (2012b). Karakterisasi dan penentuan warna biji pada beberapa genotipe kakao mulia (Theobroma cacao L.) sebagai kriteria seleksi. Pelita Perkebunan, 28, 136-144.

Anonim (2008). De Zaan: Cocoa and Chocolate Manual. Archer Daniels Midland Company.

Bahar, H. \& S. Zen (1993). Parameter genetik pertumbuhan tanaman, hasil dan komponen hasil jagung. Zuriat, 4, 1, 4-7.

Cakirer, M.S. (2003). Color as an Indicator of Flavanol Content in the Fresh Seeds of Theobroma cacao L. Thesis. The Pennsylvania State University.

Camu, N.; T.D. Winter; S.K. Addo; J.S. Takrama; H. Bernaert \& L.D. Vuyst (2008). Fermentation of cocoa beans: influence of microbial activities and polyphenol concentrations on the flavour of chocolate. Journal Science Food Agriculture, 88, 2288-2297.

Gamon, J.A. \& J.S. Surfus (1999). Assessing leaf pigment content and activity with a reflectometer. New Phytologist, 143, $105-117$. 
Garcia, E.; M. Jamilena; J.I. Alvarest; T. Arnedo; J.L. Oliver \& R. Lozano (1998). Genetic relationships among melon breeding lines revealed by RAPD marker and agronomic traits. Theoretical Applied Genetics, 96, 878-887.

Gockowski, J.; V. Afari-seva; D.B. Sarpong; Y.B. Osei-asare \& A.K. Dziwormi (2011). Increasing income of Ghanaian cocoa farmers is introduction of fine flavor cocoa a viable alternative. Quarterly Journal of International Agriculture, 50, 175-200.

Iswanto, A. \& H. Winarno (1997). Potential fine-flavored cocoa clones to produce purple and necrotic beans. Pelita Perkebunan, 13, 1-7.

Kristamtini; Taryono; P. Basunanda \& R.H. Murti (2014). Keragaman genetik dan korelasi parameter warna beras dan kandungan antosianin total sebelas kultivar padi beras hitam lokal. Ilmu Pertanian, 17, 90-103

Marzuki, I.; M.R. Uluputty; A.A. Sandra \& S. Memen (2008). Karakterisasi morfoekotipe dan proksimat pala Banda (Myristica fragrans Houtt). Buletin Agronomi, 36, 145-151.

Popov-Raljic, J.V. \& J.G. Lalicic-Petronijevic (2009). Sensory properties and color measurements of dietary chocolates with different compositions during storage for up to 360 days. Sensors, 9, 1996-2016.
Rimoldi, F.; P.D.V. Filho; M.V. Kvitschal; M.C. Gonzalvesvidigal; A.J. Pioli; S.M.A.P. Prioli \& T.R. da Costa (2010). Genetic divergence in sweet cassava cultivars using morphological agronomic traits and RAPD molecular markers. Brazilian Archives Biology and Technology, 53, 1447-1487.

Shen, Y.; L. Jin; P. Xiao; Y. Lu \& J.S. Bao (2009). Total phenolics, flavonoids, antioxidant capacity in rice grain and their relations to grain color, size and weight. Journal of Cereal Science, 49, 106-111.

Sims, D.A. \& J.A. Gamon (2002). Relationship between leaf pigment content and spectral refrectance a cross a wide range of species, leaf structures and development stages. Remote Sensing of Environment, 81, 337-354.

Soekarto, T.S. (1990). Dasar-Dasar Pengawasan dan Standarisasi Mutu Pangan. Penerbit IPB. Bogor.

Syukur, M. \& Sobir (2015). Genetika Tanaman. IPB Press. Bogor. Indonesia.

Yodmanee, S.; T.T. Karrila \& P. Pakdeechanuan (2011). Physical, chemical and antioxidant properties of pigmented rice grown in Southeern Thailand. International Food Research Journal, 18, 901-906.

$* * 0 * *$ 